\title{
What is the Uncanny?
}

\author{
MARK WINDSOR \\ Published in the British Journal of Aesthetics, 59(1), 2019, pp. 51-65.
}

Accepted manuscript; please cite from the published article

\begin{abstract}
I propose a definition of the uncanny: an anxious uncertainty about what is real caused by an apparent impossibility. First, I outline the relevance of the uncanny to art and aesthetics. Second, I disambiguate theoretical uses of 'uncanny' and establish the sense of the term that I am interested in, namely, an emotional state (a kind of anxiety) directed towards particular objects in the world which are characteristically eerie, creepy, and weird. Third, I look at Edgar Allan Poe's 'The Fall of the House of Usher' as a means of drawing out the conditions that I claim are essential to uncanny experiences, and then elaborate the terms of my proposed definition. Finally, I show how the definition accounts for two paradigmatic kinds of uncanny phenomena: cases of 'uncanny resemblances', which include twins, doppelgangers, and very lifelike representations of the human body; and unlikely coincidences of events.
\end{abstract}

\section{I.}

We all experience the uncanny: that 'horrible, eerie, shuddery feeling', as a character in one of E. T. A. Hoffmann's short stories describes it. ${ }^{1}$ This we feel in response to certain phenomena, such as strange coincidences, identical twins, and waxwork figures, which are characteristically eerie, creepy, and weird.

Since Freud published his now famous essay on the topic, the uncanny has attracted much attention in the humanities, and become a popular trope in cultural practices and art criticism. ${ }^{2}$ While Freud's broad characterization of the uncanny as an unsettling ambivalence between the familiar and the unfamiliar has been widely taken up, the reception of his deeper psychoanalytic account has been much more tenuous. In spite of its burgeoning popularity in theory and practice, little to no progress has been made since Freud's essay in reaching an understanding of what the uncanny is; indeed, it has become a commonplace in the literature that the uncanny is something that cannot be defined. The following quote from Nicholas Royle is representative: 'the uncanny is destined to elude mastery, it is what cannot be pinned down or controlled.' ${ }^{3}$ Associated in its development with late-twentiethcentury poststructuralism, and taken to be that which disrupts epistemic coherence and semantic stability, the uncanny has even become a synonym for the methodology of deconstruction. ${ }^{4}$

Barely anything on the topic has appeared in the literature of analytic aesthetics. The most notable exception is found in the work of Cynthia Freeland, who has dealt with the uncanny in the context of film analysis - in a chapter in her book on horror, and an essay which examines the

\footnotetext{
${ }^{1}$ E. T. A. Hoffmann, 'Automata', in Everett F. Bleiler (ed.), The Best Tales of Hoffmann (New York: Dover Publications, 1967), 69-103, at 81.

2 Sigmund Freud, 'The "Uncanny", in The Complete Psychological Works of Sigmund Freud Vol. 17: An Infantile Neurosis and Other Works, trans. James Strachey (London: Vintage, 2001), 217-252.

${ }^{3}$ Nicholas Royle, The Uncanny (Manchester: Manchester University Press, 2003), 15-16.

${ }^{4}$ Royle writes that 'another name for uncanny overflow might be deconstruction'. Ibid., 24.
} 
uncanny effect in Krystof Kieślowski’s The Double Life of Véronique. ${ }^{5}$ Freeland describes the uncanny as 'a broad notion that applies to phenomena, in both life and artworks, that are eerie yet enticing, strange yet familiar, creepy yet not horrific'. ${ }^{6}$ While these texts of Freeland's offer valuable insights, in neither does Freeland purport to offer an account of the uncanny; as she puts it in the conclusion of her essay on Kieślowski, 'more must be done to develop a subtler and more complete theory of the uncanny. ${ }^{7}$

The uncanny is an important topic for aesthetics because it represents an important part of our experience of many works of art. The emergence of the uncanny in art is generally located in the lateeighteenth or early-nineteenth century, in Gothic novels and Romantic short stories by writers such as E. T. A. Hoffmann and Edgar Allan Poe. In narrative works, the uncanny is often associated with themes of madness and delusion, and an ambiguous suggestion of the supernatural. The legacy of these classic uncanny stories can be found on television, in the series The Twilight Zone, Twin Peaks, and Black Mirror, for example; in films such as David Lynch's Lost Highway, David Cronenberg's Videodrome, and Stanley Kubrick's The Shining, to name a few; as well as in contemporary works of literature, including José Saramago's The Double and Mark Z. Danielewski's House of Leaves. Certain perennial themes and motifs can be identified across these works. From classic tales, such as Poe's 'William Wilson', to contemporary films, including Duncan Jones's Moon, doppelgangers continue to stalk their woeful subjects; and from the 'living' doll Olympia in Hoffmann's 'The Sandman', to the virtually-indistinguishable-from-human 'replicants' in Ridley Scott's Blade Runner, objects that trouble the boundary between the human and the non-human, the animate and the inanimate, continue to lure the artistic imagination.

In visual art, the surrealists were the first group of artists to systematically explore the uncanny in their work, including Hans Bellmer's photographic tableaus of violently-dismembered dolls, and Giorgio de Chirico's paintings of eerily-deserted townscapes. The legacy of Bellmer's work can be seen in some of Cindy Sherman's photographs, as well as in Sarah Lucas's biomorphic figurative sculptures; whereas Rachel Whiteread's casts of interior spaces evoke the same mute, dream-like presence as de Chirico's depicted scenes. In fact, there has been something of a proliferation of the uncanny in contemporary visual practices over the last few decades-from Ron Mueck's hyperrealist polychrome sculptures, to Susan Hiller's 'paraconceptual' multimedia installations, to Ed Atkins' creepy computer-generated avatars. That the uncanny has become a trend in contemporary art has been affirmed by a number of themed exhibitions. ${ }^{8}$ Much of the contemporary visual practice that evokes the uncanny can be traced back to a long tradition of 'low' visual culture, of waxwork figures, life and death masks, polychrome religious sculptures, magic lantern shows, and phantasmagoria. Although not afforded the status of 'high' art, these may nonetheless be deserving of our aesthetic attention.

Finally, some will now know the uncanny under the rubric of 'the uncanny valley'. First proposed by the Japanese roboticist Masahiro Mori in 1970, 'the uncanny valley' describes the eerie

\footnotetext{
${ }^{5}$ Cynthia Freeland, The Naked and the Undead: Evil and the Appeal of Horror (Boulder, CO: Westview Press, 2000); Cynthia Freeland, 'Explaining the Uncanny in The Double Life of Véronique', in Steven J. Schneider (ed.), Horror Film and Psychoanalysis: Freud's Worst Nightmare (Cambridge: Cambridge University Press, 2004), 87-105.

${ }^{6}$ Freeland, 'Explaining the Uncanny in The Double Life of Véronique', 88.

${ }^{7}$ Ibid., 104.

${ }^{8}$ These include Mike Kelley's The Uncanny, at Sonsbeek 93, Arnhem, The Netherlands, 1993, later restaged at Tate Liverpool in 2004, Bruce Grenville's The Uncanny: Experiments in Cyborg Culture, Vancouver Art Gallery, 2002, and The Unhomely, Kettle's Yard, Cambridge, 2003-2004.
} 
effect of humanlike figures that are too lifelike. ${ }^{9}$ As advances in technology enable increasingly lifelike human representations, in both two and three dimensions, and new, increasingly realistic modes of image consumption, such as virtual reality, the effect of the uncanny valley becomes ever more pertinent to art and culture.

In his essay, Freud located the uncanny as a 'province' in the field of aesthetics. While it may not be aesthetic by nature (it is not, for example, something we would normally think of as an 'aesthetic property'), it is clear that the uncanny is integral to our aesthetic appreciation of many works of art. What is at stake in understanding the uncanny is an understanding of an important aspect of our art and culture.

At the outset of his essay, Freud noted that 'the word [uncanny] is not always used in a clearly definable sense', but that 'we may expect that a special core of feeling is present which justifies the use of a special conceptual term' ${ }^{10}$ If the uncanny is going to be of proper use in theoretical and critical discourse, then we should be able to say what it means. While it may be true that uncanny phenomena, insofar as we experience them as uncanny, 'cannot be pinned down or controlled', I see no good reason to suppose that the concept of the uncanny is 'destined to elude mastery'. In this paper, I want to take us back to the theoretical roots of the uncanny, to pick up where Freud left off in seeking out its 'special core of feeling'.

II.

It is important to clarify at the outset that I do not aim at a definition that will capture all uses of the term 'uncanny', either in common parlance or in theory. The usage of the term that I am interested in exploring here is largely the same as that which Freud investigated in his paper, which has been adopted primarily in art theory and criticism. In this core, Freudian usage, 'uncanny' is taken to refer to a kind of feeling - one which is had in response to certain kinds of phenomena, including doppelgangers or doubles, waxwork figures, corpses, dismembered limbs, automata, coincidences, presentiments (which come true), and other apparently supernatural or magical phenomena, such as apparent hauntings and magical powers. As Freud puts it, these phenomena 'are undoubtedly related to what is frightening - to what arouses dread and horror'. ${ }^{11}$

Since the uncanny became a popular theoretical trope, its use has extended far beyond that which Freud originally intended. In some cases, 'uncanny' no longer even refers to a kind of feeling, or to the kinds of phenomena that arouse that feeling, but is rather used as an abstract critical tool, which can, it seems, be applied to virtually anything. ${ }^{12}$ Used in this way, 'uncanny' becomes synonymous with a methodology or approach to discourse. Such abstract theoretical uses as this are beyond the scope of this paper.

More pertinently, there are theoretical usages of 'uncanny' that do refer to a kind of feeling, but not the same kind of feeling that I am interested in here. What I have in mind are uses of the term that describe an existential feeling of unhomeliness. The most developed account of such a feeling of

\footnotetext{
${ }^{9}$ Masahiro Mori, 'The Uncanny Valley [From the Field]', trans. Karl F. MacDorman and Norri Kageki, IEEE Robotics \& Automation Magazine 19 (2012), 98-100.

${ }^{10}$ Freud, "The "Uncanny", 219.

${ }^{11}$ Ibid.

${ }^{12}$ In one paper, for example, the uncanny is used as a means of approaching advertisements for Wrigley's Doublemint chewing gum. The author writes that in his view 'the uncanny should be read as an ideologeme-an ideological structure that consistently reappears across vastly different narrative contexts - as much as it represents an aesthetic [or] in Freud's words, a "theory of feeling"'. Michael Arnzen, 'Supermarketing the Uncanny: Anxiety at the Point of Sale', Paradoxa 3 (1997), 311-603, at 572.
} 
uncanniness can be found in the context of Heidegger's philosophy. ${ }^{13}$ For Heidegger, uncanniness represents the fundamental state of our being in the world ('Dasein'), namely, that of our not-beingat-home in the world ('unheimlich', un-homely), which manifests in a feeling of anxiety or dread ('Angst').

Consider the feeling of unreality described by the narrator, Antoine Roquentin, in Sartre's novel, Nausea:

I gripped the volume I was reading tightly in my hands, but the strongest sensations were blunted. Nothing looked real; I felt suddenly surrounded by cardboard scenery which could suddenly be removed. ${ }^{14}$

Now contrast this with another passage in Nausea, in which Roquentin describes the effect of a statue in a town square:

there is something dry and evil about it, a delicate touch of horror. This is due to that fellow up there on his pedestal. When they cast that scholar in bronze, they turned him into a sorcerer. ... He isn't alive, true, but he isn't inanimate either. A vague power emanates from him, like a wind pushing me away. ${ }^{15}$

The feeling of unreality described in the former passage is less about objects in the world than it is about Roquentin's sense of his own place in the world - a sudden and disturbing sense of his notbeing-at-home in the world. In contrast, the feeling described by Roquentin in the second passage is directed towards a particular feature of the environment - the statue.

One way of distinguishing these affective states would be to say that where the former describes a mood, the latter describes an emotion. Emotions are directed at particular objects in the world, whereas moods are not. Emotions are selective and exclusive, whereas moods are global and inclusive. ${ }^{16}$ In the former passage, it is the protagonist's feeling of unreality that changes the way the world appears to him; in the latter, it is a particular, identifiable object in the environment that affects him and focuses his attention. Thus, moods and emotions can be seen as having opposite directions of fit: whereas moods colour everything that comes into one's purview, emotions are responsive to particular objects in the world.

My aim in this paper is to provide an analysis of the uncanny as an emotion: an affective state directed toward particular objects in the world. ${ }^{17}$ More specifically, in what follows, I analyse the uncanny as a kind of object-directed anxiety. ${ }^{18}$ According to cognitive theories of emotion, emotions possess cognitive states directed at objects which are subsumable under general evaluative criteria. ${ }^{19}$ For example, an object of fear is subsumed under the general evaluative category of 'the dangerous'.

\footnotetext{
${ }^{13}$ See Katherine Withy, Heidegger on Being Uncanny (Cambridge, MA: Harvard University Press, 2015).

${ }^{14}$ Jean-Paul Sartre, Nausea, trans. Robert Baldick (London: Penguin, 2000), 113.

${ }^{15}$ Ibid., 46-47.

${ }^{16}$ See Noël Carroll, 'Art and Mood: Preliminary Notes and Conjectures', The Monist 86 (2003), 521-555, at 526-529.

${ }^{17}$ It is true that, grammatically, we do not use 'uncanny' to describe an emotion. I cannot say that 'I feel uncanny', but I can say that I have 'a feeling of the uncanny'. In this respect, the uncanny is comparable to the sublime, which also refers both to the object and to the experience of the object ('the feeling of the sublime'). I do not think the category of emotion is sufficiently well-defined to prima facie exclude the uncanny; albeit, one may prefer to think of the uncanny as an emotional experience, rather than an emotion simpliciter.

${ }^{18}$ Of course, not all anxiety is object-directed. In other words, anxiety can either be a mood or an emotion.

${ }^{19}$ Carroll, 'Art and Mood', 522.
} 
Moreover, these cognitive states are what differentiate one emotion type from another. Approached on this model, the uncanny involves characteristic feelings or affects. Typically, these are characterized in terms of shivers, shudders, creeps, chills, hairs standing on end, crawling skin, and so on. But what defines the uncanny as an emotion, and what causes these characteristic bodily feelings, are the thoughts pertaining to the object. Not all affective states - including moods - admit of such analysis, however. As such, the analysis of the uncanny that I offer in these pages does not exhaust the affective states which the term has been used to describe, and which may be relevant to art and aesthetics.

There may, for example, be cases, such as de Chirico's paintings, that are apt to be analysed in either sense of 'uncanny'. There may also be cases that arouse the uncanny both as a mood and an emotion, where each of these is mutually reinforcing, and where it may not, in practice, always be possible to draw a sharp line between the two. Freeland notes, for example, that the evocation of the uncanny in Lynch's Eraserhead is remarkably sustained throughout the entire film. ${ }^{20}$ Eraserhead evokes an uncomfortable mood of alienation through its bleak, industrial mise-en-scène, and its distinctive presentation of images and sounds, which are often close up and abstracted, distorted and made strange. But punctuating the presentation of this unheimlich cinematic world are particular uncanny objects and events which focus and amplify the viewer's feelings of anxiety: a spewing 'manmade' chicken, a seemingly part-alien-part-human baby, spectral figures, and transportations to ambiguous, dream-like worlds. The mood of uneasiness evoked by the film's audio-visual presentation cues the audience to experience these particular objects and events as threatening and strange; and, vice versa, these uncanny objects and events contribute to the mood of uneasiness that pervades the whole. ${ }^{21}$

The important point to recognize here is that, whatever similarity they share on a phenomenological level, these two kinds of experience of uncanniness - an existential mood of alienation or unhomeliness on the one hand, and a feeling directed towards particular objects in the world which are creepy and weird on the other - are analytically distinct. ${ }^{22}$ As such, each requires a different theoretical approach.

I focus here on the uncanny as an emotion for two key reasons. First, I think that it accounts for the bulk of the phenomena that we tend to describe as 'uncanny' in common parlance. Typically, when we describe something as 'uncanny', we are pointing towards features of the object which are identified as the cause of the response, even if these features remain somewhat mysterious. Second, I think that this sense of the term is primary in art theory and criticism. This may largely be due to the influence of two classic papers on the topic, namely those of Freud, and a forerunner to Freud's essay by the German psychiatrist, Ernst Jentsch, titled 'On the Psychology of the Uncanny'; as well as, more recently, Mori's 'uncanny valley' thesis. ${ }^{23}$ All these authors approach the uncanny by examining the kinds of objects which elicit it.

From here on, when I speak of 'the uncanny', I mean it in this sense of an affective state directed at particular objects in the world which are characteristically eerie, creepy, and weird. My

\footnotetext{
${ }^{20}$ Freeland, The Naked and the Undead, 226.

${ }^{21}$ For an account of the interaction between mood and emotion in film, see Carl Plantinga, 'Art Moods and Human Moods in Narrative Cinema', New Literary History 43 (2012), 455-475.

${ }^{22}$ In the sense that it denotes one's orientation to an environment, the literal translation of the German word 'unheimlich', 'unhomely', maps onto the uncanny as a mood more closely than the English word 'uncanny', which suggests something more particular. My point is that it may be best to think of these as two different concepts.

${ }^{23}$ Ernst Jentsch, 'On the Psychology of the Uncanny (1906)', trans. Roy Sellars, Angelaki: Journal of the Theoretical Humanities 2 (1997), 7-16.
} 
aim in defining the uncanny is to specify what it is about these objects that cause them to be experienced as such. What are the conditions under which we attribute this strange, elusive property - this 'delicate touch of horror'?

\section{III.}

Consider the following passage from the opening of Poe's classic tale, 'The Fall of the House of Usher':

I looked upon the scene before me . . upon the bleak walls - upon the vacant eye-like windows ... there was an iciness, a sinking, a sickening of the heart ... What was it, I paused to think - what was it that so unnerved me in the contemplation of the House of Usher? It was a mystery all insoluble; nor could I grapple with the shadowy forces that crowded upon me as I pondered. ${ }^{24}$

Now, fear is generally defined in terms of the apprehension of danger: an object must be seen or interpreted by the individual as posing a threat to her well-being in order for it to elicit a fear response. Richard Lazarus proposes that fear not only involves the apprehension of a danger, but 'an immediate, concrete, and overwhelming physical danger ${ }^{25}$ It is true that the protagonist in Poe's story evaluates the House of Usher as a threat, but not any kind of physical danger, and certainly not an immediate or overwhelming physical danger; the protagonist cannot even identify the source of the threat, and this very mystery is part of what upsets him. The label best applied to such an emotional state is anxiety.

Lazarus describes the object of anxiety as 'an uncertain, existential threat'. ${ }^{26}$ Stanley Rachman describes anxiety as 'a tense and unsettling anticipation of a threatening but formless event; a feeling of uneasy suspense' ${ }^{27}$ The passage from Poe nicely illustrates how apt the uncanny is to be analysed in terms of anxiety. The protagonist appraises the house as a threat, but a threat that is uncertain, tenuous, and elusive. Anxiety accounts for the subtle nature of the threat issued by the uncanny object; as Rachman writes, 'when feeling anxious, the person has difficulty in identifying the cause of the uneasy tension or the nature of the anticipated event or disaster. The emotion can be puzzling for the person experiencing it. ${ }^{28}$

Consider some other examples of uncanny phenomena. A waxwork figure does not pose an immediate or identifiable threat to a person's well-being, and it is unlikely that it would be appraised as such. Visitors to Madame Tussaud's do not run away in terror from the exhibits, as one might do from a spider - even from a harmless spider - if one is afraid of spiders. But waxworks do create an uneasy tension that is characteristic of anxiety. Waxworks may be evaluated as a threat, but a threat that is uncertain, tenuous, and elusive. Likewise, a strange coincidence-say, repeatedly encountering the same number throughout the day, which might suggest something ominous and fateful going ondoes not pose any immediate or identifiable physical threat to my well-being, as much as it might unnerve me.

\footnotetext{
${ }^{24}$ Edgar Allan Poe, 'The Fall of the House of Usher', in Selected Tales (London: Penguin, 1994), 76-95, at 76.

${ }^{25}$ Richard Lazarus, Emotion and Adaptation (Oxford: OUP, 1991), 122.

${ }^{26}$ Ibid.

${ }^{27}$ Stanley Rachman, Anxiety, $3^{\text {rd }}$ edn (New York: Psychology Press, 2013), 3.

${ }^{28}$ Ibid.
} 
Clearly, though, not everything that is an object of anxiety is also an object of the uncanny. What is it about uncanny phenomena that, from the first-person point of view, they share in common such that we distinguish them as such? Let us pick up where we left off the opening of Poe's tale. Following his initial approach to the house, there grows in the mind of the protagonist a 'strange fancy' - a fancy 'so ridiculous', he tells us, that he mentions it only to show the 'vivid force of the sensations which oppressed' him:

I had so worked up my imagination as really to believe that about the whole mansion and domain there hung an atmosphere peculiar to themselves and their immediate vicinity - an atmosphere which had no affinity with the air of heaven, but which had reeked up from the decaying trees, and the grey wall, and the silent tarn - a pestilent and mystic vapour, dull, sluggish, faintly discernible, and leaden-hued.

Shaking off from my spirit what must have been a dream, I scanned more narrowly the real aspect of the building. ${ }^{29}$

Here, the protagonist finds himself caught between two incompatible positions. For a time, he cannot decide the nature of his experience of the house and its environs. More specifically, he cannot decide what of his experience of the house is real and unreal. Thus, he describes his experience of the 'mystic vapour' as of something vivid and fanciful, perceived and imagined. Until he firmly decides that it ' $m u s t$ have been a dream', the distinction, for the protagonist, between dream and reality is suspended.

The uncanny has often been associated with such a blurring of the categories of truth and fiction, reality and imagination. Royle writes, for example, that the uncanny 'involves feelings of uncertainty, in particular regarding the reality of who one is and what one is experiencing, ${ }^{30}$ But merely having uncertainty about what is real is not sufficient for uncanniness. Most of us, I imagine, will be acquainted with the semi-conscious state between sleeping and waking called 'hypnagogia'. This transitional state of consciousness can produce such disturbing experiences as lucid dreams, sleep paralysis, and hallucinations. Not being able to decide whether or not one is dreaming tends to be an unsettling experience; but not necessarily an uncanny one.

What distinguishes the uncanny character of the protagonist's experience of the House of Usher is the suggestion of its having a supernatural character. The description of its 'vacant eye-like windows' suggests an animate presence of house, that the house might, in other words, be haunted; and the description of the 'mystic' vapour is suggestive of occult, magical powers. This phraseology, combined with the protagonist's reported sense of unease and puzzlement, subtly-covertly, evenevokes in the reader a feeling that there is something uncanny about the house. The house and its environs are not fully of this world, it seems. It is just these apparently supernatural properties of the house and its surrounds that cannot be countenanced by the protagonist, and which confer its peculiarly puzzling character. The fact that the protagonist ascribes his incongruous experience to an increase of superstition is telling. It is in virtue of these apparently supernatural properties that he decides his experience ' $m u s t$ have been a dream'.

The idea that the uncanny involves the dubious appearance of the supernatural can be traced back to Freud's account. Contrary to how it is often presented in the literature, Freud does not explain all instances of the uncanny in terms of repression. Freud's account of the uncanny is actually best thought of in terms of two distinct theories: one having to do with the return of repressed infantile

\footnotetext{
${ }^{29}$ Poe, 'The Fall of the House of Usher', 78.

${ }^{30}$ Royle, The Uncanny, 1.
} 
sexual complexes, and another, more often overlooked theory, which has to do with the apparent confirmation of 'surmounted primitive beliefs'.

According to the latter theory, we all inherit, both on a phylogenetic and ontogenetic level, 'primitive' beliefs in magical and animistic phenomena, such as belief in the 'omnipotence of thoughts' and the existence of spirits, which, Freud assumes, as educated adult Westerners, we have largely, but not totally, 'surmounted'. When something appears to take place in reality which confirms any such surmounted primitive belief, we experience, or at least or are apt to experience, the phenomenon as uncanny. ${ }^{32}$ If, for example, as a child I used to believe in ghosts, and have now surmounted this belief, and one night I see a ghost-like apparition floating down the corridor, I will be apt to experience the apparition as uncanny.

As I have argued elsewhere, compared to his better-known theory of the 'return of the repressed', Freud's theory of surmounted primitive beliefs provides a relatively coherent and persuasive explanation for why we experience certain phenomena as uncanny: because they create the dubious appearance of the supernatural in the context of one's experience of reality. ${ }^{33}$ However, this theory of Freud's also faces significant problems. These pertain to the developmental commitments of the account. The idea that we all inherit beliefs in magical and animistic phenomena, both from our collective and individual past, and 'surmount' these beliefs later in life, is a lot to subscribe to. Moreover, and perhaps more importantly, it does not seem right that in order to experience something as uncanny it is necessary that a belief pertaining to some apparently supernatural phenomenon first needs to have been 'surmounted'. What if I had never believed in the existence of ghosts? Does that mean I cannot experience the ghost-like apparition floating down the corridor as uncanny?

Rather than define the uncanny in terms of 'primitive' beliefs in magical and animistic phenomena which have been 'surmounted', I suggest that this dubious appearance of the supernatural can be better understood in terms of an apparent impossibility. When the uncanny is characterized in terms of an elision of the categories of waking and dreaming, reality and imagination, what this characterization describes is not merely having uncertainty about what is real, but rather having uncertainty about what is real caused by an apparent impossibility.

One of my reasons for choosing the passage from Poe's 'the House of User' above is that it exemplifies the oftentimes elusive nature of the uncanny object, which is to say, it is often not clear what it is about some uncanny phenomenon that causes it to be experienced as such. Now, for something more explicit, consider the following scene from Lynch's Lost Highway. Near the beginning of the film, one of the two leading male characters, Fred Madison, is approached at a party by a slim, pale, sinister-looking man. This 'Mystery Man' tells Fred that they have met before. Fred does not recognize the man, and asks him where he thinks they met. The Mystery Man replies: 'At your house. Don't you remember? . . In fact, I'm there right now' ${ }^{34}$ At first, Fred is incredulous. Then the Mystery Man produces a mobile phone and suggests that Fred rings his house, which he does, hesitantly. Apparently, the same Mystery Man answers on the other end. The stage direction here is revealing: 'Fred, mirthful at first, as if it is a party trick of some kind, suddenly turns serious'. Angrily, Fred demands to know who the Mystery Man is and how he got into his house. 'The man laughs - identical laughs — both over the phone and in person', and asks for his phone back. ${ }^{35}$

\footnotetext{
${ }^{31}$ See Freud, "The "Uncanny", 245-252.

${ }^{32}$ It is not clear whether or not Freud intends to present this condition as sufficient for uncanniness.

${ }^{33}$ Mark Windsor, 'Freud on the Uncanny: A Tale of Two Theories', Philosophy and Literature (forthcoming).

${ }^{34}$ David Lynch, 'Lost Highway_The Screenplay' (1995) <http://www.lynchnet.com/lh/lhscript.html> accessed

7 April 2018.

${ }^{35}$ Ibid.
} 
This scene is remarkably effective in arousing in the audience the somatic register of the uncanny-in Hoffmann's phrase, that 'horrible, eerie, shuddery feeling'. The Mystery Man's 'identical laughs' are truly chilling. Such I propose is what defines the uncanny: an anxious uncertainty about what is real caused by an apparent impossibility.

The definition can be expressed more precisely as follows:

I experience $x$ as uncanny if and only if (1) I experience $x$ as some concrete object or event;

(2) I have an experience of $x$ that is incongruous relative to what I believe is possible, which

(3) causes me to have uncertainty about $x$, which (4) causes me to direct feelings of anxiety towards $x$.

First, some caveats. This definition is intended to capture what it means undergo an emotional episode of uncanniness. This does not imply, however, that one cannot accurately describe something as uncanny without undergoing such an episode. As with other emotion terms, 'uncanny' is often used in a dispositional sense to identify something as the kind of thing that is apt to be experienced as such. This accommodates works of art that explore uncanny themes, but which do not have an uncanny effect on the audience. ${ }^{36}$ Moreover, some works of art may be better understood as expressions of uncanniness than evocations of it. For example, de Chirico's eerie townscapes may be understood as expressing how the world appears to someone experiencing the uncanny, even if they do not arouse the same feeling in the viewer. ${ }^{37}$ In any case, to identify something as uncanny in a dispositional sense, or to identify a work as being expressive of the uncanny, still requires the ability to identify an object as an instance of the relevant evaluative criteria, which it is the aim of the definition to specify.

Let me now offer some explanation of each of the conditions.

(1) The uncanny always involves having uncertainty about what is real. 'Reality', however, is an especially slippery notion. The first condition delimits the relevant sense in which the uncanny is always about what is real: the object is always, in the first place, experienced as something concrete and particular. This condition represents the 'familiar' part of the ambivalence between the familiar and unfamiliar that is often used to characterize the Freudian uncanny in its broadest sense. A corollary of this condition is that abstract objects cannot be experienced as uncanny. Scientific proofs or philosophical arguments may represent apparent impossibilities that cause anxious uncertainty about what is real; but they cannot be experienced as uncanny if they are not experienced as concrete. $^{38}$

It is also important to note that this condition generally excludes fictional objects as candidates for uncanny experiences. ${ }^{39}$ Given that many paradigmatic cases of uncanny phenomena come from fiction, this is something that needs to be addressed. There is a loose sense in which the definition does apply, as it stands, to fictional cases; that is, if the conditions are applied from a perspective that is internal to the fictional world in question. That is the perspective I adopt in this paper when talking about fictional uncanny objects. To speak accurately, however, the definition must be adapted to the fictional case. When speaking of the uncanniness of, say, the House of Usher, to

\footnotetext{
${ }^{36}$ Greg Currie and Jon Jureidini discuss the distinction between uncanny effects that are internal or external to narrative works in 'Art and Delusion', The Monist 86 (2003), 556-578, at 560-561.

${ }^{37}$ Compare Jenefer Robinson's discussion of Edvard Munch's The Scream in Deeper than Reason: Emotion and its Role in Literature, Music, and Art (Oxford: OUP, 2005), 282-283.

${ }^{38}$ The physical notation of such a proof or argument, of course, could be. Imagine that you jotted down a philosophical paradox in a notebook, and the next day you looked at it, it appeared that the handwriting had subtly changed, that it was no longer your own.

${ }^{39}$ There are possible exceptions, such as hallucinations. Phantom limbs do not exist in the present, but they are experienced as concrete objects nonetheless.
} 
accurately describe my experience, I must say that I fictionally experience the house as some concrete object; that I have a fictional experience of the house which is incongruous relative to what I believe is possible in the world of 'the House of Usher'; and so on. ${ }^{40}$

To do justice to the complexity and nuance of uncanny fictions would require a separate discussion. One important feature of the uncanny in fiction that is worth highlighting here, which Freud first identified and numerous writers have since elaborated, is that not all fictional worlds have the same capacity to elicit uncanny effects. Fictions that openly adopt a fantastical world-view generally preclude the uncanny because what would be incongruous relative to what is believed possible in the real world will typically not be incongruous relative to what it believed possible in said fictional worlds. In fairy tales, witches that fly on broomsticks, talking animals, spirits, spells, and shapeshifters are not even incongruous, let alone incongruous relative to what is believed possible in those worlds. To put the point positively, a fictional world must be sufficiently congruous with the actual world to have uncanny potential. Moreover, it can be observed that, at a general level, the more realistic a representation is, the greater potential it will have to evoke the uncanny. Call this principle 'uncanny realism'.

Finally, it is also worth noting here that applying the definition to fictional cases need not commit me to take sides on the vexed debate concerning the so-called 'paradox of fiction'; that is, to whether or not, for example, I literally do experience the House of Usher as uncanny when reading Poe's tale, or whether my emotional response is rather some make-believe or quasi form.

(2) The second condition describes the moment when the world of normal experience is turned on its head: when it becomes strange, weird, and unsettling. This represents the 'unfamiliar' part of the ambivalence between the familiar and the unfamiliar which Freud identified. The phrase 'incongruous relative to what is believed possible' captures the fact that what is experienced is not actually impossible, but rather that it suggests or points towards something that is. The object or event is experienced as an apparent impossibility.

(3) Normally, when something happens in reality that contradicts what one believes, one simply revises one's belief. If I do not believe that there is milk in the fridge, and, when I open the fridge, I see a bottle of milk, I soon revise my belief about the contents of my fridge. With the uncanny, there is no such easy resolution. One does not revise one's beliefs about what is possible as easily as one's beliefs about the contents of fridges. Both the experience of reality and the belief about what is possible hold competing truth claims. The incongruity between these mental states- the doxastic and the experiential-pertaining to the object is one that demands resolution. Either the relevant belief about what is possible must be revised, or the incongruous experience of the object must be disavowed as false. (Albeit, disavowing one's experience as false does not necessarily make that experience go away.) Once the protagonist decides that his experience of the vapour 'must have been a dream', we are presented with a sober account of the building's façade. Alternatively, the protagonist may just have come to believe that there are such things as mystic vapours. To the extent that the incongruity remains unresolved, one has uncertainty about the object.

(4) Most apparent impossibilities are not experienced as uncanny; nor, perhaps, are most apparent impossibilities that cause uncertainty about what is real. Recall how in the scene from Lost Highway, Fred first responds mirthfully to the Mystery Man's apparent bi-location 'as if it were a party trick of some kind'. Stage magicians specialize in presenting audiences with the illusion of impossible events that take place in the here and now. Moreover, a successful magic show will engender total bafflement in the spectator as to how the illusion has been achieved. Magic shows are an illuminating comparison case to the uncanny, for it may be that the only thing that separates the

\footnotetext{
${ }^{40}$ I draw here on Kendal Walton's Mimesis as Make-Believe: On the Foundation of the Representational Arts (Cambridge, MA: Harvard University Press, 1990).
} 
one from the other is this: whereas magical performances play with the audience's grasp of what is real, uncanny phenomena pose a serious threat to it. ${ }^{41}$

The uncanny object need not, and typically does not, pose any physical danger to one's wellbeing. Rather, and in all cases, it poses a psychological threat: a threat to one's grasp of reality. Having anxious uncertainty about what is real is one thing; having anxious uncertainty about what is real caused by an apparent impossibility is quite another. Hence, the uncanny is often associated with themes of madness and delusion in narrative works. As the narrator in Guy de Maupassant's short story 'Le Horla' reflects, once he starts to experience a series of inexplicable, apparently supernatural events: 'I don't know what to think. A wise man doesn't commit himself'. ${ }^{42}$ Always disturbing, perhaps thrilling too, to experience the uncanny is to loose one's grip on reality - to experience a firsthand glimpse of madness.

\section{IV.}

I now want to briefly show how the proposed definition can be applied to two broad categories of paradigmatic uncanny phenomena: first, what can be called cases of 'uncanny resemblances', which include waxwork figures and identical twins; and second, unlikely coincidences of events. My intention is that these categories should be broad enough to give a sense of how the definition captures the bulk of the phenomena that we tend to experience as uncanny.

While it may be easy to identify an apparent impossibility with phenomena that have a supernatural character, such as apparent hauntings or magic powers, even if that supernatural character is quite subtle, as in the case of Poe's mystic vapour, it may seem less easy to identify an apparent impossibility with such phenomena as waxwork figures and identical twins, which, on the face of it, are just an ordinary part and parcel of the concrete world. But in fact, such objects do often carry an effect which comes close to the supernatural character of the mystic vapour. Note how Roquentin describes the statue in the town square in terms of magic — a 'sorcerer' who emanates a 'vague power'. Very lifelike polychrome statues often function in religious contexts to convey something of the 'aura' or 'presence' of the holy persons they represent. The surrealists were attracted to such lifelike objects as mannequins, dolls, prosthetics, and mechanical automata because they had the character of what they called 'the marvellous'.

Just as much as mystic vapours and haunted houses, waxworks can create the appearance of the impossible by creating the appearance of an object that is at once animate and inanimate. The waxwork is uncanny to me because I experience it, at some level, to some sufficient degree, as if it were a living human being. This may involve just a flickering sense of the figure's animation; one that

\footnotetext{
${ }^{41}$ For example, the same apparent act of telepathy that a magician performs on stage is apt to be uncanny in a different context. In a particularly unnerving scene in Cronenberg's film Scanners, the character Kim Obrist feels herself being telepathically communicated with — being 'scanned' — by a pregnant woman's unborn baby in a hospital waiting room. For an account of stage magic, see Jason Leddington's 'The Experience of Magic', Journal of Aesthetics and Art Criticism 74 (2016), 253-264. Pertinently, in the case of magic, Leddington speaks of 'a moment of cognitive failure that is nevertheless "contained" by the knowledge that "it's just a trick”. In this respect, despite being totally baffled, the spectator remains master over the illusion'. Ibid. 260261.

${ }^{42}$ Guy de Maupassant, 'Le Horla', in The Mountain Inn and Other Stories, trans. H. N. P. Sloman (Harmondsworth: Penguin, 1955), 30-55, at 44.
} 
takes place at the back of the mind, so to speak. Marina Warner describes the hyperrealist figurative sculptures of Ron Mueck thus: 'These imitations of bodies shiver on the very verge of life, it seems. ${ }^{43}$ Jentsch's central thesis is that the uncanny essentially involves an experience of 'psychical uncertainty'. Jentsch discussed in his essay how 'semi-conscious secondary doubts' can be 'repeatedly and automatically aroused anew' upon the perception of a very humanlike figure. ${ }^{44}$ Thus, it may be that the level of experience that gives rise to this incongruity is cognitively impenetrable. Knowing that a lifelike figure is not alive does nothing to change the low-level incongruous experience of it that it is. Alternatively, one may have an uncanny sense that a human being is inanimate. Jentsch refers to how, in 'The Sandman', Hoffmann subtly introduces to the reader the sense that Nathanael's beloved, the ingenious 'living' doll Olympia, may not be all that she seems, by describing her repetitive monosyllabic utterances, fixed expression, and waxen face, before the terrifying moment of revelation in which she is torn apart during an argument between her two jealous creators.

Uncanny resemblances of this kind can also be found between living individuals, as in the cases of doppelgangers, identical twins, and clones. In these cases, the category violation that takes place on an experiential level is not between the concepts 'animate' and 'inanimate', but rather between one individual and another. Twins are creepy because they appear to be the same person. My doppelganger freaks me out because he appears to be me. Twins and doppelgangers trouble our sense of a unique individual as a unique individual. Consider Louis Sass's analysis of Diane Arbus's famous photograph, Identical Twins, Roselle, N.J. 1967:

the more one looks at the face of either girl, the more her face is likely to seem ineffably particular, like a version of something other and realer than itself to which it seems, somehow, to allude. As one's gaze moves to the other twin, however, the same thing happens again; now this one seems to be a copy of the other. ${ }^{45}$

Thus, the very reality of each of the girls is made dubious by the other. Which one is the original? Which one the copy? Sass's analysis captures the sense in which twins and doppelgangers create the same doubtful tension between reality and appearance that characterizes the experience of waxworks and other lifelike figurative representations.

Consider now the second paradigmatic kind of uncanny phenomena, coincidences. A coincidence, I take it, comprises two or more events that are meaningfully related, which do not share any discernible causal connection. Of course, no matter how improbable a coincidence is, that does not make it impossible. Sometimes, though, coincidences are so striking or remarkable that it can seem that the composite events must share some objective connection beyond that of mere chance or contingency; 'too much of a coincidence', so to speak. This, in turn, can create the appearance of the impossible. Poe deftly captures the impossible character of such remarkable coincidences when he writes that:

There are few persons, even among the calmest thinkers, who have not occasionally been startled into a vague yet thrilling half-credence in the supernatural, by coincidences of so

\footnotetext{
${ }^{43}$ Marina Warner, Phantasmagoria: Spirit Visions, Metaphors, and Media into the Twenty-first Century (Oxford: OUP, 2006), 55.

${ }^{44}$ Jentsch, 'On the Psychology of the Uncanny'. 12.

${ }^{45}$ Louis Sass, The Paradoxes of Delusion: Wittgenstein, Schreber, and the Schizophrenic Mind (Ithaca, NY: Cornell University Press, 1994), 116.
} 
seemingly marvellous a character that, as mere coincidences, the intellect has been unable to receive them. ${ }^{46}$

Note here how Poe sets up a dichotomy between 'the calmest thinkers' on the one hand, and the 'supernatural' and the 'marvellous' on the other. Generally speaking, the marvellous character that Poe talks about correlates to the perceived degree of improbability of the coincidence. There are a number of different supernatural phenomena the existence of which such strange coincidences could suggest. It could be, as when thinking of a person who you then unexpectedly bump into on the street, an instance of precognition; or it could be that some supernatural being or power, such as may be called 'Fate', had predetermined the events to coincide with one another. Uncanny stories are often characterized by an ambiguous and ominous sense of fate which looms over its characters.

A nice example of how such apparently impossible coincidences can cause anxious uncertainty about what is real can be found in Poe's 'the House of Usher'. Unable to sleep one night due to a raging storm, the protagonist reads aloud to his disturbed companion, the owner of the eponymous house, Roderick Usher, from an old romantic tale, the 'Mad Trist' of Sir Launcelot Canning. Repeatedly, sounds pertaining to events recounted in the tale are heard by the protagonist coinciding in 'exact similarity of character' with sounds coming from about the house. ${ }^{47}$ 'It was ... the coincident alone which had arrested my attention', the protagonist notes, 'for . . . the sound, in itself, had nothing which should have interested or disturbed me' ${ }^{48}$ What seems to be impossible is the apparent connection between the fictional events described in the 'Mad Trist' and the actual sounds heard coming from the house. Surely, there cannot be any causal relation between these events; yet that is exactly the marvellous scenario that the protagonist is confronted with: an impossible intrusion of fiction into reality.

V.

According to my analysis, to speak of the uncanny as having 'a special core of feeling' may be misleading, for the uncanny is not merely a feeling. What allows us to distinguish as uncanny 'things which lie within the field of what is frightening' is a particular kind of cognitive evaluation of an object or event: an uncertain threat to one's grasp of reality caused by something that is incongruous relative to what is believed possible. ${ }^{49}$

The analysis I have offered is not intended to capture all common parlance uses of the word 'uncanny' (albeit, I do intend that it should account for the bulk of the phenomena that we tend to think of and describe as such); nor is it intended to capture all of the theoretical uses of 'uncanny' which have proliferated in discourse since around the mid-twentieth century. Any definition that would be extensionally adequate to such a task is bound to be uninformative. Rather, the aim has been to provide an analysis of the concept of the uncanny in what may be called its central theoretical usage, which describes the effect of certain phenomena that are characteristically eerie, creepy, and weird. What these phenomena share in common is that they create the dubious appearance of the supernatural in the context of one's experience of reality.

I have left many interesting and pressing questions about the uncanny untouched. For a start, why, given that it is essentially a negative emotion, do we value and enjoy works of art that evoke it?

\footnotetext{
${ }^{46}$ Edgar Allan Poe, 'The Mystery of Marie Rogêt', in Selected Tales (London: Penguin, 1994), 199-250, at 199.

${ }^{47}$ Poe, 'The Fall of the House of Usher', 92.

${ }^{48}$ Ibid.

${ }^{49}$ Freud, 'The "Uncanny", 219.
} 
Call this the 'paradox of the uncanny'. Given how prominent the uncanny has become in art and culture, and given that up till now barely anything on the topic has appeared in the literature of analytic aesthetics, my hope is that this paper will both provide a foundation for future discussions, and help garner recognition of the uncanny as a topic deserving of sustained aesthetic enquiry. 